\title{
Belongings: Oral History, Objects and an Online Exhibition ${ }^{1}$
}

JANIS WILTON

\begin{abstract}
We are an innovative virtual heritage centre similar to an online museum. Our website presents an exciting program of online exhibitions you can view featuring community collections, family belongings and people's memories. ${ }^{2}$
\end{abstract}

$\mathrm{T}$ The New South Wales Migration Heritage Centre (MHC) was established in 1998. Since 2003 its physical presence has been located within Sydney's Powerhouse Museum and it has had the strategic brief to record the memories of ageing migrants before their stories are lost. ${ }^{3}$ The Centre is, however, a museum without a collection; a heritage authority without heritage sites; a cultural institution whose main presence is in cyberspace. Among its high profile projects is one entitled Objects through time and another Belongings. Both focus on the ways in which objects can convey aspects of the migration experience. Belongings, the focus of this 
article, presents the remembered experiences of people who migrated to Australia after World War II and seeks to highlight significant features of their experiences through asking them to share their memories and to nominate and talk about significant objects. ${ }^{4}$ As a project it grew out of movable heritage policy work within state government agencies, and its initiators - John Petersen, Kylie Winkworth and Meredith Walker - were central players in this development. It was also inspired by the National Quilt Register of the Pioneer Women's Hut at Tumbarumba. ${ }^{5}$

With its object-centred approach and accompanying edited interview transcripts, Belongings provides a focus for exploring the messages and emphases that emerge when oral history interviews concerned with migration have the specific brief to ask about material culture and its significance. Belongings also enables an exploration of the layering of those messages that emerges when object captions are located back in the context of the oral history interviews from which they were extracted. As a virtual exhibition, Belongings also provides the opportunity to consider the challenges for museums (virtual and real) when they need to condense the richness of migrant oral histories and life stories to captioned objects that can be put on display.

\section{SIGNIFICANT OBJECTS}

Belongings takes as its focus objects selected as significant of key aspects of interviewees' migration experiences. It is a focus guided by three complementary practices. The first is the museum practice that seeks the stories that give meaning to objects; the second is the emphasis on assessing significance of sites and moveable heritage that sits within Australian state and national heritage guidelines; and the third is the emphasis on community consultation and participation that is at the core of many of the Migration Heritage Centre's projects. ${ }^{6}$ These practices invite community members to seek out and conserve objects that tell stories about their migration experiences; invite internet audiences to interact with the material form of the objects through description and through viewing (although, as with museums and their glass cases, the internet does not allow audiences to touch); and provide access to why individuals identify particular objects as significant. 
The images anchoring the migration stories told by each interviewee are images of objects and the statement of the exhibition's purpose underlines the central role of objects:

Belongings tells the stories of some [post war immigrants] through personal mementos, photographs and memories. Some are treasured objects brought from the 'old country'; others are souvenirs of the journey out; or keepsakes from their first home or job. All help us understand how migration changed their lives and through the cultures and traditions they brought with them the lives of all Australians forever. ${ }^{7}$

In describing the processes involved in seeking participants, curator and coordinator Andrea Fernandes explains that the core of the project is to seek objects that capture aspects of the migration story and to encourage participants to see the value of those objects, their stories and their role as heirlooms that, within families and communities, can carry the migration experience across generations. ${ }^{8}$ She openly admits that these are not life story interviews, although elements of life stories emerge. They are interviews and encounters that ask people to select items that relate to their pre-migration lives, their migration journeys and their early years of settlement.

Sometimes participants readily have objects in mind. At other times prompts and questions, especially shaped by interviews conducted within participants' homes, produce items. The selection of objects often becomes a joint enterprise between interviewer and interviewee and the emphasis overtly remains on experiences surrounding first migrating to and settling in Australia. ${ }^{9}$ The stories and memories provoked by the objects, however, are those remembered and shared by participants. As Fernandes explains:

Personal, first-hand experiences of post-World War Two migrants are recorded through their special memorabilia, or belongings, in English. We meet people in their homes - the nation's museums - and they share with us stories behind their mementos. ${ }^{10}$

She identifies the project as important for its ability to raise 'the profile and place of personal memorabilia', validate 'migrant communities, their experiences and belongings' and make 'heritage 
and history more accessible and appealing' ${ }^{11}$ She emphasises her role in setting up partnerships with community groups and in managing and editing the work coming through them.

Certainly, a visit to the online exhibition provides an enticing example of a community based 'e-exhibition' that takes on board the challenges of an online presence with its need for accessible, attractive, layered, informative and engaging material. ${ }^{12}$ Here are individuals from a variety of cultural backgrounds sharing stories about their lives and about objects that, for them, capture particular aspects of their migration experiences. You can see the owners and their chosen items. You can read about the items and, if you choose, you can read the accounts of their migration experiences drawn from oral history interviews. As Fernandes explains:

The final interview is reduced and edited for brevity and clarity. ... the main oral history text appears in bite-sized paragraphs which is good for the web. ${ }^{13}$

For oral historians, the treatment of the interview material invites assessment within the rich literature about editing for publication. ${ }^{14}$ However, here the interest is not in the processing of the oral history material. Rather, it is in the ways in which Belongings enables an evaluation of how objects identified through oral history interviews can convey aspects of the migrant experience and how an emphasis on those objects still within the family home helps to create particular migrant narratives.

Which objects do participants select? What does that selection say about the impact of migration on their lives, and about those aspects of their lives that they want to highlight to a wide public? What overall impression of immigration in post World War II Australia or, indeed, which migrant narratives - emerge from viewing the objects and their stories as presented in Belongings?

At my time of browsing (April 2008), the e-exhibition presented the memories and objects of 107 Australians from 36 different cultural backgrounds. ${ }^{15}$ Of these, I focused on the 84 immigrants who came from non-English-speaking backgrounds. It was a focus guided by another current project whose concern is to track and document the patterns and experiences of Australians from non-Englishspeaking backgrounds who settled on the New England tableland in northern New South Wales in order to link those patterns and 
experiences to the individuals, objects and sites that help to tell their stories. The emphasis in the New England project arose from the relative neglect of immigrants from non-English-speaking backgrounds in the existing literature. ${ }^{16}$ In this context, an evaluation of the objects in Belongings offered ideas about the types of objects and stories that might inform the New England project as well as contributing to a broader understanding of the place of objects in migration memories.

Of the 84 individuals from Belongings whose contributions are analysed here, the earliest year of arrival in Australia was 1947 and the most recent 1974. Each participant had on display edited brief life stories drawn from their oral history interviews, and one to six objects captioned by excerpts from the interviews. The selected objects are, by implication, the objects symbolising key aspects of interviewees' migration experiences and the labels or captions accompanying them capture that significance. These are, in essence, the objects and labels that would be on display in a museum exhibition.

I viewed and read about a total of 185 objects. ${ }^{17}$ Importantly, it was clear that the objects were primarily portable items. A feature of the migration experience is the need to leave many things behind and to make decisions about what can or should be transported to a new home or place of refuge. For refugees, the choice - if there is one - is even more restricted.

I pulled together the objects and their 'captions'. I categorised them by themes and emphases. I contemplated the messages conveyed by this collection of items and captions. Among dominant themes were those relating to work, migration journeys, cultural traditions and, across all categories, an emphasis on items that are or can become heirlooms and mementos: objects that can pass the stories to other audiences and down the generations. Here, there is space for only a small sample.

Work was represented particularly in tools of trade brought from countries of origin and is a repeated presence. Anne Marie Birdsey talks about the 'trunk [that] contained all of my father's implements for his shoemaking trade'; Alexandra Rezko the 'blade of the scythe' brought to Australia by her father and 'used... extensively on our small acreage at Huntley'; and Brunhilde Srejic 'the hairdressing 
implements' that she had hoped would help her to 'continue my trade as a women's hairdresser'. ${ }^{18}$

The memories provoked by objects relating to work experiences speak of hopes, disappointments, frustrations, achievements and recognition. Tarsilla Cunial recalls 'the courage to come to Australia' that was provided by bringing her dress design and teaching books from Italy 'in case I had the opportunity to work in that area'. For Anne Marie Birdsey's father there was disappointment: the trunk full of shoemaking equipment was not put to use because 'Australia wanted labourers and he worked at the Port Kembla steelworks and Riverstone meatworks. It just wasn't him. He was a shoemaker.' Jacqueline Giuntini's father experienced the frustration of taking two years to get an Australian driving licence due to the English language test when, prior to migration, 'he had an international licence [and] could travel all over Europe.' For others, the work items chosen provide evidence of success. Jan De Kruiff's business card symbolizes his success in establishing his own business in Australia and triggers pride in his assistance in establishing 'the Manual Activity Centre in Albury... [which] provides a space, tools and equipment for older men and women to build things; carpentry, welding, and the like.' He notes: ' I have always used my trade skills throughout my working life, at home and at the MAC Centre.' Franca Arena's sense of achievement focuses on a letter from an Australian official asking her 'to teach elementary English to immigrants on the boat'. As Arena explains:

Being a girl by myself I might have been in a bit of danger, but the fact I was the teacher [meant] I was treated deferentially by the other immigrants. By the time we reached Fremantle, I was given a cheque for $£ 20$ which I didn't expect at all. I came over on a $£ 10$ passage so I had made a profit before I even arrived!

Also well represented are those objects which capture aspects of the movements across borders and across the world that sit at the core of the experiences of post-World War II migrants to Australia. The emphasis is on the journey that finally ends with settlement in Australia.

There are the trunks and cases used to transport worldly possessions. Amelia Brinkis refers to 'an old crate box' that was used 
to 'transport our belongings' and how her husband recycled it 'to make a coffee table'. George Kotsiros chooses a suitcase and explains how he carried it 'everywhere, bringing the light green, metal case with me across from Greece.'

There are the visas and documents which mark periods of waiting and hoping:

I stayed five months in Austria and the United Hias Service gave us food and accommodation. They fixed my travel to Australia and this is my visa. (Ivan Devai)

Once we arrived in Bonegilla ${ }^{19}$, our papers were processed and we were given a meal. Not many of us ate as we did not feel very hungry. (Eleonora Conolly)

There are postcards and mementos from the ships that provided transport to Australia. Rozalia Cetinich fondly produces 'the postcard of the boat I arrived on', and Manuela Provenzano has 'this ashtray... taken from the ship we migrated on as a souvenir'.

For those who came as refugees, the privations and traumas of war and displacement are kept alive through carefully selected keepsakes. Arthur Hill has the spoon he used at Paszow and Mathausen concentration camps: 'if I lost it I would have to use my fingers to eat.' Elizabeth Mergl's choice is a 'little clock'. She explains:

It was 1944 and we managed to walk to Austria in two weeks. By then I had my first child... This little clock was our timing for the baby, to know what time it was to have food...

Cultural traditions coupled with links to family and friends, with fears and hopes for the survival of those traditions and with a sense of the distances created by migration are evoked through objects relating to food, clothing and pastimes. Dragoslava Williams still has the 'traditional Serbian blouse and skirt her mother had made and embroidered' for her and that she had worn when the family fled from Yugoslavia. Vicki Drosos keeps her wedding 'dress from Greece' as a 'souvenir [of] good and sad memories'. The sad memories include leaving all her relations behind in Greece. Maria Goulding brought and kept her Dutch coffee pot because 'using it 
again in Australia brought back memories of Holland, I guess - the family mealtimes, the smell of the coffee.' And Peter Gwodsz expresses delight that his 'father sent over my accordion' because 'three generations have played the accordion: me, my father and grandfather.'

There are also objects that tell stories about the place of education, language and religion as migrants move across cultural and geographical distances. Family and community are also central. Spanning all categories, there is a conscious emphasis on the role of an object as a memento of a person, a place, an event and often as an item that belongs across generations. Inga Krain explains:

[When] we set up our first home [in Australia], one special belonging was my family sugar cube holder. [It] is from my grandmother, on my father's side.

Domenica Scarcella points to a hand painted fine bone china statue of the Madonna: 'It was acquired in Italy in the 1850s and passed on to me through my husband's grandmother and mother. It was a wedding gift to his grandmother from the local friars.' For Stephanie Jakovac and Gina Bortoloni-Papa their chosen items evoke memories of growing up and of family stories. Stephanie Jakovac collects 'house keys on my return journeys to Slovenia. They remind me [of] growing up and are simply so beautiful.' Gina Bortolini-Papa has a hand-made scarf that was 'used for sore throats, earaches and headaches by my mother to soothe our ailments.' As she explains: 'It had a magical quality and I plan to tell my grandchildren all the stories my mother would tell me when she was comforting me with this healing scarf.'

Browsing the objects owned and selected as significant by participants in Belongings highlights key migrant narratives and illustrates the ways in which particular objects and their captioned stories drawn from oral history interviews are moving objects and objects of memory. These objects offer rich messages about the important role material culture can play in saving and triggering memories and in measuring those experiences which individuals regard as epitomising key aspects of their lives as migrants.

Belongings, however, offers more than a collection of objects and their captions. 


\section{OBJECTS IN CONTEXT}

As an online exhibition, Belongings has space for more text and content than is possible or, at least in museum practice, advisable in a 'real' exhibition in a museum. After viewing an object and its accompanying interview excerpt you can move beyond the object and its caption. You can place the object and its story in the broader context of an interviewee's life story. The messages and significance become more layered. As well, objects other than those extracted for exhibition emerge - lost objects, abandoned objects, transitory objects, incidental objects - and offer different insights into the connections between memories, material culture and the migration experience. An example illustrates this layering.

Chafic Ataya (born in Lebanon) first travelled to Australia on board the SS Misr in 1947. First interviewed by Andrea Fernandes, she subsequently recommended him as a participant for a multimedia project produced by the Sydney Morning Herald. Excerpts from his and other video interviews can be viewed and heard on the Sydney Morning Herald website. ${ }^{20}$ Extracts from his original interview with Fernandes are included in Belongings. The lilt, tone and texture of his voice and gestures are straightened into a clear and structured narrative. The bones of his story remain. Key moments and key items anchor the flow. The starting point - visually and structurally on the website - are the objects identified as capturing significant and symbolic moments in his migration experience. Ataya's six significant objects ${ }^{21}$ with their accompanying interview excerpts are depicted in Figure 1.

Based on these excerpts, the significance of the objects for Ataya emerge because of their association with his education and creativity (the exercise book of poems); grandfather and other family members and the sense of adventure that helped to propel him towards emigration (the binoculars); skills and pastimes (the backgammon set); work in Australia (the wallet); a visit home to Lebanon (the postcard); and the support and recognition gained from community and family (letter from Sir Nicholas Shehadie).

Locating these excerpts in the edited transcript of the oral history interview with Ataya that is available in the online exhibition invites more nuanced meanings and significance.

His exercise book of poems attests to his early education, his creativity and his literacy in Arabic but it is also significant as a 


\section{Figure 1}

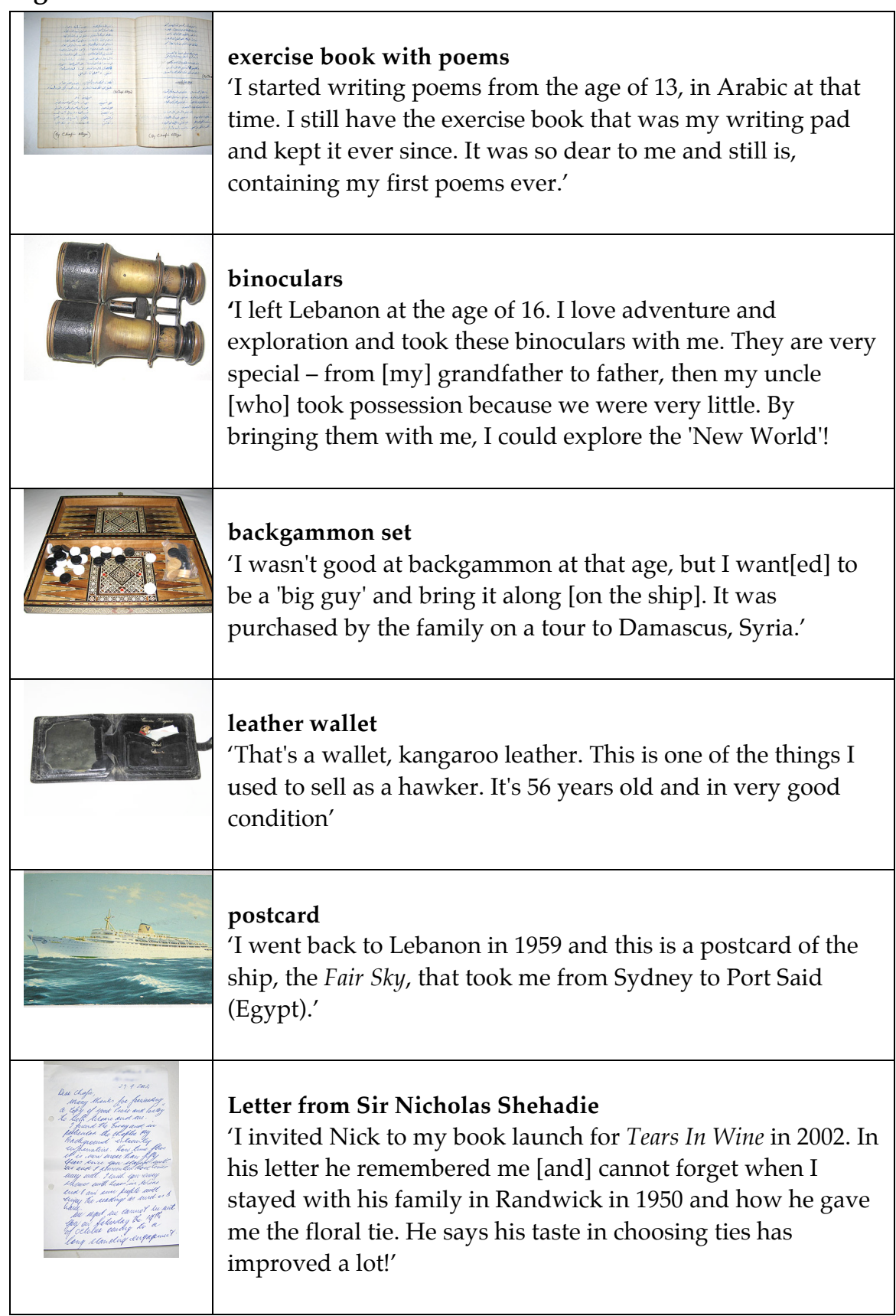

symbol of Ataya's desire for intellectual freedom. The book is mentioned in the context of his decision, as a boarder in a monastery, 
not to 'become a novice monk'. He says: 'I like to be free. Always free. The freedom of intellect. I started writing poems from the age of 13'.

The binoculars are an important heirloom passed down from Ataya's grandfather and, for Ataya, also link to what he sees as his sense of adventure and exploration. The context of their use in Lebanon - 'While we were at home we used to look towards our vineyard [to see] if anyone's trespassing or stealing grapes or figs' provide a fleeting reference to the work and homelife that sustained Ataya's family in Lebanon before the death of his father when Ataya was aged seven. And the binoculars emerge later in his story when, en route to Australia, the ship stopped at Durban and Ataya and a friend 'started to climb hill after hill and I thought I would see all of Africa with the binoculars!' The binoculars come to symbolise Ataya's desire to see the world, as well as his ability to watch those who trespass on his land. Significantly, Ataya also observes: 'I want to leave the binoculars for my children'. The heirloom and its significance will be passed across another generation.

The extended interview excerpt for the backgammon set locates Ataya's lack of skills in the game because, at the time, 'I was involved with studies and writing'. This connects the game back to his love of learning and creativity. He also recalls that the set was purchased when the family made a visit to Damascus and that it is 'Syrianmade, handmade. Very expensive.' Status becomes associated not just with who played the game but also with the story and craftsmanship of the backgammon set and its acquisition.

The leather wallet kept as a memento of his days hawking goods in north-west New South Wales gains greater significance for its association with the job, as a hawker, which saw him rebelling against working as a store salesman ('somehow I felt sorry for people when we buy for $\$ 1$ and sell for $\$ 2$ ') and working long hours for poor pay in a relative's house and garden. It also begs for the memories that flesh out his recollections of this 'nomadic life' in which 'I followed the shearers and [would] wait 'til they have a break. I camped on riverbanks amongst Indigenous people, sharing their dreams and listening to their awe inspiring tales.' These comments provoke imaginings about what it was like for this young man from Lebanon, to live and work in the vast and lightly populated expanses of rural Australia. 
The postcard of the ship that took Ataya back to Lebanon in 1959 is evocative of the frequent return visits immigrants have paid to their home countries. For Ataya, however, this was not a brief return visit, a summer spent catching up with family and with childhood surroundings. It was a visit that lasted for twenty-five years, saw him marry and have children and had him working in marketing and as an English language teacher - jobs far from the work he had been doing in Australia and that he was subsequently able to do on his return to Australia in 1987. War in Lebanon sent him back to Australia.

With eloquent symmetry, Ataya's last object and its interview excerpt, the letter from Sir Nicholas Shehadie, include reference to Ataya's continued writing of poetry, that creative endeavour begun at a young age in Lebanon and symbolised in his first significant object, the exercise book of poems. On the Sydney Morning Herald website you can hear and see him reading one of his poems. It is an experience that emphasises the power and layers of meaning that can only be conveyed through sound. Another significance of this item is its reference to the support Ataya received from the Shehadie family when he first came to Australia, and the way that support is captured partly through the mention of a lost object - 'the floral tie'. The tie is described elsewhere in the interview: 'I used to come to his [Nicholas Shehadie's] shop every day and he gave me a beautiful tie; it was floral; green, red and yellow and wide. I was sad I lost it in my many moves.'

Ataya's selected objects have layered stories. They begin with the excerpts chosen to act as captions for the objects. They continue with explorations of the objects in the context of the rest of Ataya's interview. Complexities and nuances emerge. And these more complex and nuanced perspectives on Ataya's view of his migration experiences are heightened when other objects in the interview are identified and when the surviving and tangible objects that Ataya still owns are accompanied by other items, large and small, extant or lost.

The postcard depicting the Fair Sky and marking Ataya's return to Lebanon in 1959, can be linked to other ships and forms of transport mentioned throughout his interview and signifying the constant journeying which has shaped his life and the emotions attached to that journeying. There is the car that, in early 1947, took Ataya from Beirut to Palestine 'before it was partitioned' and marked 
the start of his migration journey to Australia. 'I didn't realise I could be so sad until after I left', he said. There were the trains that took him onto Cairo: 'On the train I met Australian boys who were sailors. They taught me how to open a bottle of beer.' (And a bottle of beer enters the narrative as a distinctly Australian item.) Then there was the month long trip on the SS Misr, with 200 to 250 people packed into a dormitory and a very rough passage across the Australian Bight. There was the cargo ship which next took him to his aunt in New Zealand where 'I finished my high school [and] I started to write poetry in English.' Differences over religion - linking perhaps to the early decision that intellectual freedom was more important than security in living as a Catholic monk in Lebanon - had Ataya returning to Australia by flying boat in 1950 and, after a month, by train to Walgett in central New South Wales - '24 hours - never again!'.

In Walgett he worked as a salesman in a relative's shop and then eventually struck out on his own, 'bought a van, hawking from one town to another.' In 1959, Ataya 'took up driving cabs': 'Some passengers would call me unfavourable names as a foreigner, but the best I heard was to go back from where I came.' It was in that year that Ataya took the Fair Sky and went back to Lebanon, keeping the postcard as a memento. From this point in the online version of his interview, Ataya no longer mentions the forms of transport that kept moving him around the world and around jobs and signifying the physical, emotional, occupational and cultural journeys that characterise his life. This, instead, is captured by him talking about spending time 'in different parts of the Arab world' for work and also spending time in Cyprus, Canada, the USA and Lebanon before returning to Australia.

Presented in this way, objects of transport - ships, boats, trains, planes, cars - both generic and specific are significant in Ataya's story for the way they capture and symbolise the constant moving that characterises his migration experiences. And it is a moving that goes beyond the single direction implied in migration objects selected primarily because they tell the story of migrating to (and settling in) Australia. Migration is never a one way journey.

There are other objects mentioned in the online version of the interview that offer other insights into Ataya's migration experience. There is the note written to Ataya's aunt in New Zealand by 
Australian soldiers on leave near his hometown in Lebanon during World War II. The note - presumably no longer in existence - in English, simply said 'take me to New Zealand as a student'. The note marks both Ataya's first encounter with Australian soldiers - he persists in calling them 'Anzacs' ${ }^{22}$ throughout the interview - and his initiative in seeking to leave Lebanon. It was the same aunt - his father's sister - who, following his father's death, sent clothes and money in order to assist the family to survive. And it was the same aunt who, when the SS Misr was late leaving Cairo, responded to a telegram for assistance by sending Ataya $£ 10$ - 'I was rich!'.

The online interview also links to three photographs depicting aspects of Ataya's migration story. Only one - a photograph taken in a café in Kings Cross - is mentioned in the online interview. The other two are linked into the interview at relevant moments. The first, quite possibly a photograph taken to send home to family in Lebanon, has Ataya standing with the family with whom he stayed when he first arrived in Melbourne. They are photographed, well dressed and posing in front of what is presumably his host family's home. Here is comfort, family, respectability, safety: a good beginning for a new life on the other side of the world.

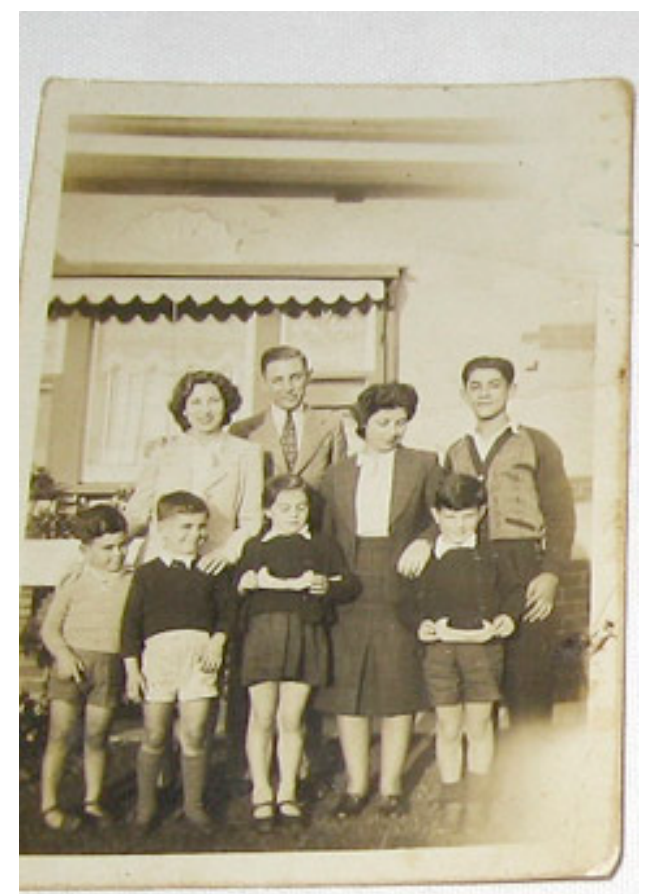

Chafic Ataya with relatives outside his first home in, Melbourne, May 1947 
The second photograph is more informal, a snapshot, showing Ataya with two other young men after a shooting expedition in Walgett. Here is a taste of bush Australia. The trophy - a large spread eagled hawk - hanging between them, and Ataya's somewhat laconic commentary: 'That's when we used to go shooting. Either pigs or hawks, whatever we could get money for. I'm on the left hand side with a gun. In those days it meant nothing.'

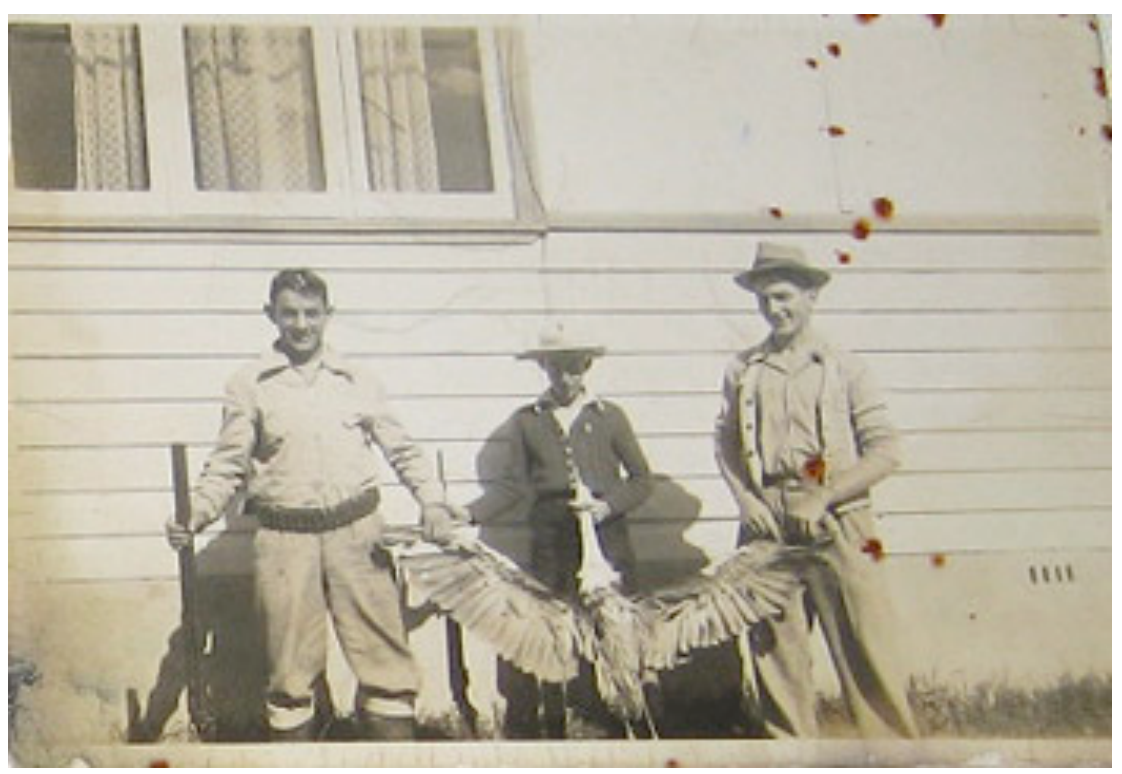

Left to right: Chafic Ataya, Leslie Corban and Michael Malouf, Walgett, 1953

The third photograph links directly to a story in the online version of the interview. Ataya is talking about the period when he was hawking in north-west New South Wales and he used to visit Sydney regularly to get stock. While there he became involved with nightclubs and, with other immigrants, could be found frequenting the cafés that were starting to alter the smells, services and interiors of Sydney life. Ataya links it to his Walgett shooting photograph and to his life in rural areas: 'I was always connected with Kings Cross and the bush [at] the same time. This photo was taken by a United Nations photographer'.

The photographs, with their focus on his early years in Australia and as photographs probably sent home to family, are laden with messages about the success, wisdom, safety, exotic nature - shooting eagles in the bush - and sophistication - drinking coffee with artists 
and being photographed by a UN photographer - of his new life. They sit waiting further interrogation and, as with other objects both those still extant and those sitting among his memories - gain greater meaning as they are located within the contexts of Ataya's oral history interview and life story.

By layering Ataya's and the other participants' stories, by inviting viewers first to experience significant objects and their stories and then to place those and other objects in the context of the migrant stories recounted through oral history interviews, Belongings enables rich encounters with the place of material culture in memories. The objects kept as mementos to mark significant moments and memories reveal more stories and associations, and from within remembered experiences emerge a range of other objects - big and small, often no longer in existence - that mark and relate the complexities of migrant experiences.

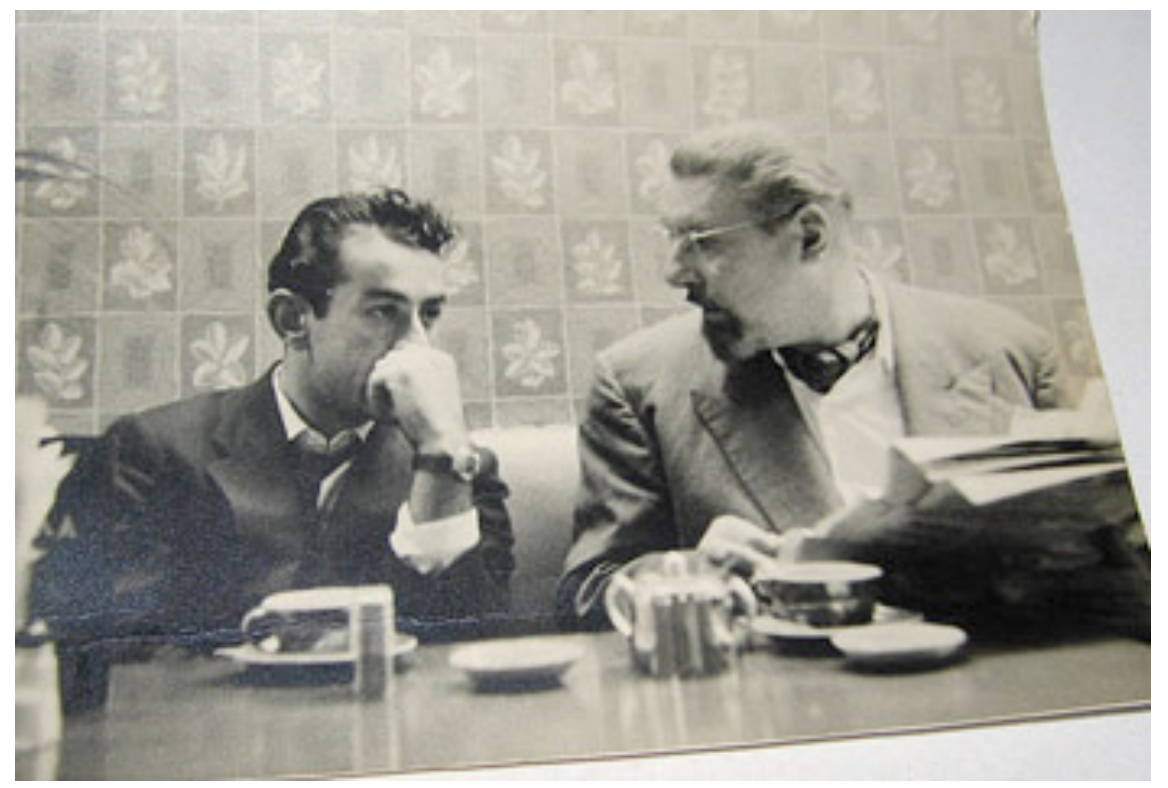

Left to right: Chafic Ataya and Austrian artist, Hans Roth, Modca Café, Kings Cross, Sydney, 1955

\section{CONCLUSION}

Belongings provides a rich and varied sampling of the ways in which objects link to memories and, through oral history interviews, become a means to convey important messages about the migrant experience. The 'e-exhibition' invites viewers to meet individual migrants, their stories and treasured objects that highlight aspects of 
their stories. It also invites and enables a more layered and varied encounter with moving objects and their place in memory. By focusing on the objects selected as significant by participants and extracting those objects to form themes, Belongings highlights familiar migrant narratives and memories which connect to objects that, by choice or fortune, have been kept and have been selected to symbolise significant aspects of an individual's migrant experience: work, journeying, war and displacement, cultural traditions, heirlooms and mementos. These are the objects consciously chosen. The objects put on display.

Belongings also provides an opportunity to look beyond the objects on display and to explore other stories and other objects. By providing fuller, if edited, excerpts from the oral history interviews, Belongings makes it possible to add further stories and meanings to the selected objects. It is also possible to track other objects moving through the interview. These emerge as integral parts of the migration narratives. They are not the objects kept as mementos or heirlooms, or the objects kept and consciously selected because they evoke a particularly significant aspect of the migration experience. These are lost or transitory objects. They are items mentioned as a part of a story. Tracking them adds further layers to the migration narratives and can deepen and sometimes complicate the messages conveyed by selected objects.

\section{ENDNOTES}

${ }^{1}$ An earlier version of this article was presented to the $15^{\text {th }}$ International Oral History Conference in Guadalajara, Mexico, in September 2008 under the title 'Moving objects.' It is part of an ongoing exploration of the place of objects in memory. For the initial exploration see Janis Wilton, 'Telling objects: material culture and memory in oral history interviews', OHAA Journal, 30, 2008, pp41-49. For assistance in refining the paper, particular thanks to Helen Andreoni, Joe Eisenberg, Andrea Fernandes and John Petersen, and to the refereeing process at $P H R$.

${ }^{2}$ About us, Migration Heritage Centre New South Wales www.migrationheritage.nsw.gov.au

3 For an overview of the history of the Migration Heritage Centre see Jennifer Barrett and John Petersen, 'The museum, democracy and domesticity: who's on whose web?', Paper to Museums Australia National Conference, Canberra, May 2007.

${ }^{4}$ Belongings, Migration Heritage Centre New South Wales, www.belongings.com.au

${ }^{5}$ National Quilt Register, http:/ / discover.collectionsaustralia.net/nqr/ 
${ }^{6}$ For some of the literature discussing objects and their meanings see Wilton, 'Telling objects', p41; on objects and significance see Significance: A Guide to Assessing the Significance of Cultural Heritage Objects and Collections www.collectionsaustralia.net/sector info item $/ 5$; and on the community consultation approach within the MHC see Barrett and Petersen, 'The museum, democracy and domesticity'.

${ }^{7}$ Belongings - home, $\underline{w w w}$.belongings.com.au

${ }^{8}$ Andrea Fernandes, Personal communication, 25 August 2009.

${ }^{9}$ ibid.

${ }^{10}$ Andrea Fernandes, Belongings: post-World War 2 migration memories and journeys, Paper presented to Moving Cultures, Shifting Identities Conference, Flinders University, Adelaide, Australia, December 200, www.migrationheritage.nsw.gov.au/belongings/about-

belongings/belongings-paper/. Note: Fernandes observes that many interviewees '... have a first language other than English'. Yet resources and perceptions about audience have meant that English is the language of the interviews.

${ }^{11}$ ibid.

${ }^{12}$ For a discussion of the Migration Heritage Centre's view of the nature and possibilities of 'e-exhibitions' and how they can further the Centre's engagement and collaboration with a range of communities see Barrett and Petersen, 'The museum, democracy and domesticity'.

${ }^{13}$ Fernandes, p9. Fernandes emphasises that the original audio files are available, subject to the approval of participants.

${ }^{14}$ Some of the debates and issues that could inform an evaluation of the editing of oral history interviews done for Belongings are raised in Tim Bowden, 'Let's not throw the baby out with the bathwater', OHAA Journal, 27, 2005, pp.63-68. Bowden's article is in response to Rebecca Jones, 'Blended Voices:crafting a narrative from oral history interviews', OHAA Journal, 26, 2004, pp4-51.

${ }^{15}$ The exhibition is ongoing. One of the benefits of an online exhibition is that it can be open-ended. More objects, stories, insights are added as they are documented.

${ }^{16}$ The project has produced an online database and thematic study. Both can be accessed from $<$ http://hfrc.une.edu.au/heritagefutures/neimmigrants/>.

${ }^{17}$ The next innovation - if technology, resources and participants allow would be to be able to listen to the interview excerpts online, and to hear the interviewees talking about their objects and telling their stories

${ }^{18}$ Images of the objects, the captions as well as profiles of interviewees are available from the Belongings website.

${ }^{19}$ Bonegilla was a former army camp that became a migrant hostel for accommodating and processing the influx of post-war immigrants. It was situated inland on the Victorian side of the twin towns of AlburyWodonga on the border between the states of New South Wales and Victoria.

20 'Chafic Ataya, Lebanon', The first wave: beyond a white Australia, http:/ / www.smh.com.au/multimedia/misr/ataya.html

${ }^{21}$ The images used in this article are reproduced with the permission of Chafic Ataya and the NSW Migration Heritage Centre. 
22 'Anzac' is the acronym for Australian and New Zealand Army Corps, and has entered Australian language as a synonym specifically for Australian soldiers and generally for Australians. 